\title{
ASEAN Harmonisation; Compliance of Cosmetics Regulatory Scheme in Thailand within 5 Years
}

\author{
Neeranard Jinachai, Puree Anantachoti \\ (The Graduate Program in Social and Administrative Pharmacy, Faculty of Pharmaceutical Sciences, \\ Chulalongkorn University, Thailand)
}

\begin{abstract}
The ASEAN Harmonisation was aimed to stabilise politics, and improve economic, social, and cultural aspects of the region. In the healthcare sector, cosmetics was the first to be harmonised and committed to implement the ASEAN Harmonised Cosmetics Regulatory Scheme (AHCRS) in January 2008, with full implementation expected in January 2011. This study was conducted to determine whether Thailand has complied with ASEAN Cosmetic Directive (ACD) after 5 years of implementation in 2012. Thai cosmetics Act B.E. 2535 and ACD were compared in 2008, and in 2012. Content analysis and in-depth interview was performed. The study revealed that Thailand has highly complies with ACD in all regulated areas; (i) definition and scope of cosmetics products (ii) ingredients' listing (iii) labelling (iv) product claims and (v) good manufacturing practice. To officially implement ACD, the Thai regulator has to transpose the directive into local law. During the legal process, one might notice discrepancy between these two laws. Although the country regulator intended to fully harmonize, some minor issues such as the ingredients' listing and labelling, these cannot be implemented all at once. In summary, it can be concluded that the main objectives of AHCRS have been achieved. Harmonization in Thailand happened in an ASEAN way.
\end{abstract}

Keywords: ASEAN, Harmonisation, Compliance, Cosmetics, Directive

\section{Introduction}

Since global trade has become more competitive, the region of ASEAN ${ }^{1}$ has tried hard to build a strong economic alliance to enhance the trade facilitation ${ }^{2}$. To eliminate non-tariff barriers, ASEAN member countries have recognised the need to put in place harmonised technical regulations as one community-one standard ${ }^{1}$. Cosmetics sector was the first healthcare product sector which was claimed to be fully harmonised and implemented in the region. The Agreement on the ASEAN Harmonised Regulatory Scheme (AHCRS) was signed on the $2^{\text {nd }}$ September $2003^{3}$. The AHCRS was first implemented in all ASEAN member countries on $1^{\text {st }}$ January 2008 with the 3 years grace period commitment. All ASEAN members should have undertaken appropriate measures to adopt and implement this in 5 areas of the ASEAN Cosmetic Directive (ACD) which were (i) definition and scope of cosmetics products (ii) ingredients' listing (iii) labelling (iv) product claims and (v) good manufacturing practice (GMP). Thailand is considered a leading exporter in the ASEAN region and in particular the cosmetics sector, ${ }^{4}$ although, there has been no academic research or study performed on the compliance of Thailand to ACD after the full implementation announcement (Information on ASEAN Cosmetic Directive, 2012) .

The levels of ACD implementation could be different among member countries which depend on national regulation background. For example, Indonesia, Malaysia and Thailand, all of these countries had their existing national cosmetics laws and regulations. In order to implement the ACD in such countries, legal process to transpose the ACD content must be done. For the countries which had no existing cosmetics laws and regulations, such as Singapore, the ACD could be completely implemented. The level of ACD implementation also depends on the country context; culture, language and way of life. These different aspects may impact the level of control on cosmetics products ("Overcoming Trade Barriers From Standards and Technical Regulations," 2008).

The ASEAN cosmetics harmonisation used the EU cosmetics control as a model. The content in ACD is almost the same as the EU Cosmetics Directive. The EU Cosmetics Directive which was adopted in 1967 has finally been replaced by the EU Cosmetics Regulation which was adopted in 2009 and enforced on $13^{\text {th }}$ July

\footnotetext{
${ }^{1}$ ASEAN Comprises of Brunei Darussalam, Cambodia, Indonesia, Malaysia, Myanmar, Lao PDR, Philippines, Singapore, Thailand and Vietnam.

${ }^{2}$ ASEAN Economic Community Blueprint, online: http://www.asean.org/archive/5187-10.pdf

${ }^{3}$ Information on ASEAN Cosmetic Directive, online:

http://www.hsa.gov.sg/publish/hsaportal/en/health_products_regulation/cosmetic_products/asean_regulatory.html

${ }^{4}$ Trade statistics for international business, online: http:www.trademap.org
} 
2013. ${ }^{5}$ It is noticeable that the EU took more than 40 years to change the status of "EU Directive" to "EU Regulation". The regulation came into effect in the EU to strengthen the safety of cosmetic products and streamline the framework for all operators in the sector. The compliance with the regulations is controlled by the national or regional competent authorities in the EU member states. The ASEAN Cosmetic Directive was enforced to be fully implemented in 2011 which is at the very young stage of implementation compared with the EU directive. This could be the reason why there are still issues and problems of ACD implementation within the member countries in the region. However, ASEAN has learned a lot from EU on its implementation, so the smoothness and tone of ACD implementation is tentatively faster.

For Thailand, cosmetics is one of the healthcare products which require regulation by Thai Food and Drug Administration (FDA) for consumer protection aspect. Thailand has regulated cosmetic products since 1974. The latest version is the Cosmetic Act B.E. 2535 (1992). Therefore, to implement the ACD in Thailand, it must be transposed into Thai laws and the content must be aligned with the existing Cosmetics Act B.E. 2535. In Thailand, there are many levels of legal implementation i.e. Act, Ministry of Public Health (MOPH) announcement, and Thai FDA announcement. For the act level, the legal process takes around 7-10 years. However, for other tiny laws and regulations for example MOPH announcement and Thai FDA announcement, the timeline would take about 3-6 months(Consolidated Version of Cosmetic Regulation, 2012).

This study was to compare the ACD and Thai cosmetics regulation at the implementation baseline in 2008 and to learn the real situation including issues and problems of ACD implementation at the local level and its compliance status at the year of 2012 after 5 years of full implementation (Lor, 2011). This will also help Thailand to know its status and be able to set up a good plan or strategies for moving forward to the success of the ASEAN economic community in 2015.

\section{Methodology}

The comparative study was conducted to learn how Thai cosmetics regulation complied with ACD at 2 points; at baseline and after 5 years of ACD implementation in Thailand. The baseline timeline was 2008 which was the year of ACD implementation in the country. The study was then conducted to compare Thai cosmetics regulation after 5 years ACD implementation in 2012. Compliance in this study was defined as whether Thai cosmetics regulation conformed to ACD. The gap between the ASEAN directive and Thai regulation were identified by content analysis and confirmed by an in-depth interview which was organised among 14 key informants from both regulator and industry sectors who used to participate in ASEAN Cosmetic Scientific Body (ACSB) Meetings and/or ASEAN Cosmetic Committee (ACC) Meetings. Key informants were members of the ASEAN working group of Thailand. Similarities and discrepancies between ACD and Thai regulation at 2012 were explored based on five technical harmonised aspects ${ }^{6}$ which were:

1. Definition and Scope of Cosmetic Products.

This was to compare how Thai cosmetics Act and ACD define scope of and identify cosmetic products.

2. Ingredients' listing.

The cosmetics ingredients were a part of the harmonised areas because they impact directly on the safety of consumers. The issues to compare were category of ingredient list and ingredients within each category.

3. Labelling.

The 2 guidelines of Thai cosmetics regulation and ACD were compared in terms of required subject heading, and content.

4. Product Claims.

This study was to compare Thai cosmetics regulation and ACD on the factors of concept of claims justification and scope of cosmetics claims.

5. Cosmetics Good Manufacturing Practice (GMP).

This study intended to compare the Thai GMP and ASEAN GMP in 2 aspects; references for GMP development, and level of implementation.

Measurement was semi-structured questionnaires composed of open-ended questions in 5 technical areas. For each area, the following sequential questions were asked:

1. In the area of ("definition and scope of cosmetic products", or "ingredients' listing", or "labelling", or "product claims", or "GMP"), is Thailand cosmetics regulation "similar" or "different" from the ACD?

$\checkmark$ Similar (2.) Please explain.

\footnotetext{
${ }^{5}$ EU commission, Health and Consumer, Cosmetics Directive, online: http://ec.europa.eu/consumers/sectors/cosmetics/documents/directive/index_en.htm

${ }^{6}$ Agreement on the ASEAN Harmonised Cosmetic Regulatory Scheme, Phnom Penh, 2 September 2003, online:

http://www.asean.org/communities/asean-economic-community/item/agreement-on-the-asean-harmonised-cosmetic-regulatory-schemephnom-penh-2-september-2003
} 
2. If "Similar",

$$
\text { Different (3.) Please explain. }
$$

2.1 Was it similar at the first?

$\square$ Yes

No $(2.2)$

2.2 If it was not similar at first, when was the Thai regulation updated to comply with ACD?

3. If "Different",

3.1 What is the difference?

3.2 Why is it different?

3.3 Does Thailand have any plan to comply with ACD?

$$
\begin{aligned}
& \square \text { Yes (3.4) } \\
& \square \text { No (3.5) }
\end{aligned}
$$

3.4 How does Thailand prepare to comply with ACD? And how long will it take to prepare to comply with ACD?

3.5 Will Thailand bring the issue to ASEAN meetings to update ACD to be similar to Thai country specific requirements? What are the plans and evidence?

The data analysis was done by identifying, categorising, and summarising the collected information in five areas. The findings were then documented and reported. Data was quantitatively analysed to find out whether the 2 laws were similarly interpreted, and whether the two laws, when implemented, produced the same outcome. The study protocol was approved in April 2013 by the Ethics Committee of the Faculty of Pharmaceutical Sciences, Chulalongkorn University.

\section{Result}

Thai cosmetics regulations and ACD were compared at 2 points; base line in 2008 and after ACD full implementation in 2012. The comparison was performed on 5 technical areas which were "definition and scope of cosmetics", "ingredients' listing", "labelling", "product claims", and "GMP" to find the discrepancy between both standard requirements. The results have been shown below.

\subsection{Definition and scope of cosmetics}

The comparison of ACD and Thai cosmetics Act on the definition and scope of cosmetics is shown in the Table 1 below.

Table 1 Comparison between ACD and Thai cosmetics regulation on definition and scope of cosmetics

At baseline, the main concepts of cosmetics definition and scope of the Thai Cosmetics Act were highly similar to ACD. There was no updated law and regulation in this part. Even though, the ACD and the Thai cosmetics definition and scope were written differently, the products which were classified as cosmetics by ACD framework were also classified as cosmetic products under Thai regulation framework.

Minor differences between the scope of Thai Cosmetics Act and ACD have been notified. The cosmetics scope of Thailand is a bit wider than ACD regarding the inclusion of the "substances specifically used in cosmetics production" and "substances which were announced by the Ministry of Public Health". The definition impacted some products which in other countries were classified as general consumer products, but were classified as cosmetics products in Thailand. Sanitary pad, cool towel, and cool paper are some examples. These specific products are cosmetics in Thailand and have been controlled by the Thai FDA because of microorganism concern in such products.

In general, ACD and Thai cosmetic regulations are similar, with minor difference on the scope of function and purpose of use. For Thai regulation, the main purposes of cosmetics are for "cleaning", "beautifying", and "correcting body odour". Although the ACD had the same main focus, it was not limited to these 3 purposes. The cosmetics scope would definitely be linked to the area of claims. In Thailand, cosmetics 
claims are restricted only to "cleaning, beautifying, and correcting body odor". Indications other than specified cannot be claimed. Products such as moisturiser with whitening agent can only be claimed for "skin moisturising" or "skin nourishing", but cannot be claimed for "whitening". Key informants from industry sector criticised that these discrepancies were considered technical trade barriers to the Thai market.

\subsection{Ingredients' listing}

Thailand actually had the cosmetic ingredients' listing before ACD implementation in 2008. At baseline, both Thai cosmetics regulation and ACD had 5 ingredients' listing categories. The comparison between both laws has been shown in Table 2 .

Table 2 Comparison between ACD and Thai cosmetics regulation on definition and scope of cosmetics

\begin{tabular}{|c|c|c|c|}
\hline \multicolumn{2}{|l|}{ Baseline in 2008} & \multicolumn{2}{|l|}{2012} \\
\hline ACD & Thai Regulation & ACD & Thai Regulation \\
\hline $\begin{array}{l}\text { 1. Prohibited ingredients }(1,243 \\
\text { items })\end{array}$ & $\begin{array}{l}\text { 1. Prohibited ingredients (41 } \\
\text { items) }\end{array}$ & $\begin{array}{l}\text { 1. } \\
\text { Prohibited } \\
(1,373 \text { items })\end{array}$ & $\begin{array}{l}\text { 1. Prohibited ingredients } \\
(1,372 \text { items })\end{array}$ \\
\hline $\begin{array}{l}\text { 2. Restricted ingredients (101 } \\
\text { items) }\end{array}$ & $\begin{array}{l}\text { 2. Special control ingredients } \\
\text { (27 items) }\end{array}$ & $\begin{array}{l}\text { 2. Restricted ingredients ( } 278 \\
\text { items) }\end{array}$ & $\begin{array}{l}\text { 2. Restricted ingredients } \\
\text { (279 items) }\end{array}$ \\
\hline $\begin{array}{l}\text { 3. Colouring agents } \\
\text { (155 items) }\end{array}$ & $\begin{array}{l}\text { 3. Colouring agents } \\
\text { (147 items) }\end{array}$ & $\begin{array}{l}\text { 3. Colouring agents } \\
\text { (185 items) }\end{array}$ & $\begin{array}{l}\text { 3. Colouring agents } \\
\text { (185 items) }\end{array}$ \\
\hline $\begin{array}{l}\text { 4. Preservatives } \\
\text { (57 items) }\end{array}$ & $\begin{array}{l}\text { 4. Substances which may be } \\
\text { used in cosmetics } \\
\text { productions (13 items) }\end{array}$ & $\begin{array}{l}\text { 4. Preservatives } \\
\text { (57 items) }\end{array}$ & $\begin{array}{l}\text { 4. Preservatives } \\
\text { (57 items) }\end{array}$ \\
\hline 5. UV filters (32 items) & 5. UV filters (19 items) & 5. UV filters ( 30 items) & 5. UV filters ( 30 items) \\
\hline
\end{tabular}

Note: The number, content and details of controlled ingredients in each particular listing might be different and updated from time to time. The ACD listing was aligned with the EU directive and its updates while the Thai ingredients listing was aligned with ACD and its updated listing.

At baseline, category 1, 3 and 5 of both laws used exactly the same category names, but category 2 and 4 were called differently. Each of the 5 categories in ACD and in Thai cosmetic regulation had exactly the same meaning, but one can note that the numbers of ingredients in each category were unequal.

The reason behind the difference is that Thailand also had other relevant laws to control such ingredients. For examples, antibiotics or other pharmaceutically active ingredients classified in ACD as prohibited ingredients were not listed in the Thai cosmetics prohibited ingredient list. Because these cosmetic prohibited ingredients were already controlled by the Drug Act B.E. 2510. This kind of control reflected why Thailand had smaller number of prohibited ingredients when compare with ACD at the baseline timeline.

Thailand started to update the ingredients' listing by transposing ACD into its laws and regulation since 2008. After 5 years implementation in 2012, Thailand has complied with the ACD in all 5 categories of "prohibited ingredients", "restricted ingredients", "colouring agents", "preservatives", and "UV filters" even though the numbers and details of each particular category listing were different. This was because Thailand has a specific legal process in which the law content must be reviewed and approved by national cosmetics committees. The process usually takes 6-12 months before an official announcement in the Royal Gazette.

There are 2 examples of discrepancy in ingredients' listing of ACD and Thai cosmetics regulation in 2012. The first example is "lead acetate". It is classified as a prohibited ingredient for cosmetics in ACD, but is classified as a restricted ingredient in Thailand. The Thai National Cosmetic Committee, with supporting historical usage evidence in the country, allowed lead acetate at concentration not exceeding $0.6 \%$ to be used in hair dye products. The other example is "fluoride". Fluoride is a restricted ingredient in ACD with the maximum concentration allowance of $1,500 \mathrm{ppm}$. In Thailand, however it is classified as a cosmetic restricted ingredient with the lower maximum concentration allowance of $1,100 \mathrm{ppm}$. In Thailand, fluoride has been added in water supply system. Thus, the maximum limit was set at lower concentration for cosmetics products to prevent excess fluoride intake. These country specific requirements were already raised and have been acknowledged in the ACSB and ACC meetings. The ingredients' listing of each category in ACD has to be updated from time to time based on the EU directive. The ACD adopted cosmetics ingredients listings of the EU Cosmetics Directive 76/768/EEC. However, future amendments to the listings of the EU Cosmetics Directive will be considered and discussed by the ASEAN Cosmetics Committee before adopting by member countries.

For ASEAN, the ingredients' listing is updated twice a year according to the ASEAN Cosmetics Scientific Body (ACSB) meeting and ASEAN Cosmetics Committee (ACC) meeting. The updated ASEAN ingredients' listing is normally aligned with the updated EU ingredients' listing.

After the ACD ingredients' listing was updated, the ASEAN member countries including Thailand had to update their local ingredients' listing to comply with ACD. The updated ingredients' listing of ACD was referred to the updated listing of the EU Directive. Normally, the implementation timeline was always given to ASEAN member countries by ACC to update the local laws and regulations. In Thailand, the ingredients' listing has been intentionally and continuously updated following the updated ACD listings. However, Thailand 
has a complicated legal process in which the updated cosmetics ingredients' listing must be reviewed and considered by national cosmetics committees before transposing into Thai laws. In general, the updated ingredients' listing of Thailand was 6 to 12 months behind the updated ACD listing.

For this part, it could be concluded that Thailand has complied with ACD after its full implementation in the country in 2012. There are still gaps in the number of ingredients in each ingredient category between Thailand and ACD because of the timeline of local law process on transposing those updated ingredients' listing into local laws. The Thai FDA has adopted and implemented the ingredients' listing in ACD by transposing updated ACD ingredients' listing into Thai laws from time to time. The updated ingredients' listing could not be completely transposed in one time period. It must be based on the updated ingredients' listing in the EU directive which is reflected to the updated ingredients' listings of ACD which currently uses EU directive as a reference. This means the number of items and details of each ingredient's listing could not be fixed at any specific time period. It could be changed any time based on safety assessment and expert's opinions. The ingredients in the list could also be shifted from one to another. For example, one ingredient which used to be classified as "restricted ingredient" could be moved to "prohibited list of ingredient" depending on the safety assessment and experts" opinion. The ingredients' listing is directly related to consumers and products safety, so the Thai regulator has tried very hard to comply with the updated ingredients' listings of ACD as quickly as possible. The incompliance and/or time lag for implementation on updated ingredients' listing would definitely impact to either the consumers' safety or become a technical barrier to trade for industry sector.

This compliance of Thailand to ACD also reflected the control of the finished products in the country which were finally shifted from "product registration" to "product notification". The three levels of cosmetic products of Thailand comprising (1) special controlled cosmetics (2) controlled cosmetics, and (3) general cosmetics before ACD implementation were finally removed in 2008. All finished cosmetic products of Thailand are currently classified as one product category which is "controlled cosmetics" which required only "product notification" before placing them in the market. The compliance of Thailand in this area has a huge positive effect to industry because it truly eliminates technical trade barriers. The industry could save cost and time which occurred during the pre-marketing process. It could be said the country compliance of this area resulted in Thailand achieving the AHCRS objectives.

\subsection{Labelling}

Cosmetics product labelling means information written or printed or image on the immediate or outer packaging and any form of leaflet. Table 3 shows the comparison of labelling requirements of ACD and Thai cosmetics regulation at the baseline and after 5 years ACD implementation in 2012.

Table 3 Comparison between ACD and Thai cosmetics regulation on product labelling

\begin{tabular}{|c|c|c|c|c|}
\hline \multirow{2}{*}{\multicolumn{2}{|c|}{ Labelling Components }} & \multirow{2}{*}{$\begin{array}{l}\text { ACD } \\
(2008-2012)\end{array}$} & \multicolumn{2}{|l|}{ Thai cosmetic regulation } \\
\hline & & & Baseline (2008) & 2012 \\
\hline 1. & Product name & Required & Required & Required \\
\hline 2. & Instructions for use & Required & Required & Required \\
\hline 3. & $\begin{array}{l}\text { Composition } \\
\text { declaration }\end{array}$ & $\begin{array}{l}\text { Full ingredients listing required } \\
\text { in descending order }\end{array}$ & $\begin{array}{l}\text { Name and quantity of active } \\
\text { ingredient required }\end{array}$ & $\begin{array}{l}\text { Full ingredients listing required } \\
\text { in descending order }\end{array}$ \\
\hline 4. & Product origin & $\begin{array}{l}\text { Country of manufacturer } \\
\text { required }\end{array}$ & Manufacturer name and country & Manufacturer name and country \\
\hline 5. & Product liability & $\begin{array}{l}\text { Responsible person for placing } \\
\text { product on the local market } \\
\text { (distributor, manufacturer, and } \\
\text { importer) }\end{array}$ & $\begin{array}{l}\text { Importer name and address for } \\
\text { imported product, manufacturer } \\
\text { name and address for locally } \\
\text { made products }\end{array}$ & $\begin{array}{l}\text { Importer name and address for } \\
\text { imported product, manufacturer } \\
\text { name and address for locally } \\
\text { made products }\end{array}$ \\
\hline & Net contents & Required & Required & Required \\
\hline & Batch number & Required & Required & Required \\
\hline & $\begin{array}{l}\text { Manufacturing date or } \\
\text { Expiry date }\end{array}$ & $\begin{array}{l}\text { Manufacturing date or Expiry } \\
\text { date }\end{array}$ & Manufacturing date & $\begin{array}{l}\text { Manufacturing date is required } \\
\text { for all cosmetics products. } \\
\text { Expiry date is mandated only on } \\
\text { products with shelf-life less than } \\
30 \text { months) }\end{array}$ \\
\hline & Special precaution & Required (if any) & Required (if any) & Required (if any) \\
\hline 10. & Product type & Voluntary & Required & Required \\
\hline 11. & $\begin{array}{l}\text { Category } \\
\text { identification of finish } \\
\text { product }\end{array}$ & Not required & $\begin{array}{l}\text { 1.Special controlled cosmetics } \\
\text { 2. Controlled cosmetics }\end{array}$ & Not required \\
\hline & $\begin{array}{l}\text { Product identification } \\
\text { number }\end{array}$ & Not required & $\begin{array}{l}\text { Registration number required } \\
\text { for "Special controlled } \\
\text { cosmetics" }\end{array}$ & $\begin{array}{l}\text { Notification number required } \\
\text { for all cosmetic products }\end{array}$ \\
\hline
\end{tabular}

Note: For small packaging, "product name" and "batch number" were mandated for ACD. For Thailand, label less than $20 \mathrm{~cm}^{2}$, "product name", "instruction of use", and "notification number" were mandated.

ACD labeling requirements mentioned that ASEAN member states shall take all necessary measures to ensure that cosmetic products must be marketed only by product labels which are in full compliance with the 
ASEAN Cosmetic labeling requirements. The ACD also specified that the labeling elements should appear in English and/or national language and/or language understood by the consumer where the product is marketed.

At baseline, it was found that 6 of 12 items of Thai labelling elements were different from ACD labelling requirements. The differences at baseline were the subjects of "composition declaration", "product origin", "product liability", "manufacturing date or expiry date", "product type", "category identification" and "product identification number".

After ACD implementation, Thailand updated its labelling requirements to comply with ACD on the subject of "category identification" because Thailand re-classified the "special controlled cosmetics", "controlled cosmetics", and "general cosmetics" at the baseline timeline to only one category of "controlled cosmetics" since 2008. The Thai labelling requirements were then adopted and implemented as one standard for all cosmetics types in the country after ACD implementation. After ACD full implementation in Thailand in 2012, the differences were decreased to 5 of 12 items of Thai labelling requirements different from ACD labelling requirements which were "product origin", "product liability", "manufacturing date or expiry date", "product type", and "product identification number". The requirements which could be considered as major differences between Thai regulation and ACD are "product origin", "product liability" and "product notification number".

For "product origin", Thailand requires "manufacturer name and country" while ACD requires only "country of manufacturer". It was confirmed by Thai regulators that both manufacturer's name and country are more useful for product traceability purposes.

For "product liability", Thailand specifies that the product responsibility should belong to the manufacturers for domestic products and importers for imported products, respectively. ACD product liability is the responsible person who places the product in the market. Thai regulators said that there were a lot of cases happened in the country that the responsible person who placed the products in the markets could not be traced when there were illegal cases found during post marketing surveillance. This is the reason why the Thai FDA insists to enforce the manufacturers and importers to be legal entities for product responsibilities.

For the country specific requirement on "product notification number" of Thailand, the reason for Thai country specific requirements on "product notification number" given by key informants from Thai authority was that this number on packaging was used as a traceability tool for Post Marketing Surveillance (PMS) purposes. However, for industry perspective, the "difference" of Thai labeling requirements from ACD was considered as technical trade barriers, because the industry had to prepare a new label every time the notification number changed. Also there was "no" rule for variation or amendment process. This meant that every time there was any change made to a product i.e. formulation, product name or trade name or manufacturer, a company had to re-submit notification to the Thai FDA and the new notification number would be created. The old labels with previous notification number must be destroyed. This requirement created difficulty to product launch plans. It impacted business management relating to costs, time and resources. The country specific requirements on labeling also impacted products with the multi-languages labeling supplying worldwide, because the final packaging artwork could not be finalised until the Thai notification number was available. Also some countries did not understand or were confused on the 10 digits of the Thai notification number shown on packaging.

The labelling mandatory elements are required to be presented in Thai language except the ingredients names which were allowed to be in English. This was to ensure that Thai consumers understood product information well before selection and use.

\subsection{Product claims}

At baseline and in 2012, Thailand did not have specific laws or regulations to control cosmetic claims. Like other consumer products, the claims and advertisements were control by the Consumer Protection Act B.E. 2522 and Cosmetics Act B.E. 2535. Similarly to ACD, cosmetics claims in Thailand did not require preapproval before allowing to be published. However, the product claims and advertisement must comply with statements in the Consumer Protection Act B.E. 2522 and Cosmetics Act B.E. 2535, when there were post marketing surveillance on claims conducted by regulators. The suspected or problematic claims were judged by Thai cosmetics regulation with the similar outcome of when the same claims were judged by ASEAN claims guideline in ACD. It was then considered that the outcome on claims allowance justification was similar between Thai regulation and ACD. In 2012, Thailand still exercised the same regulation. There were no updated laws and regulation related to product claims in Thailand after ACD implementation. Please see the comparison between ACD and Thai cosmetics regulation on product claims in Table 4 below. 
Table 4 Comparison between ACD and Thai cosmetics regulation on product claims

\begin{tabular}{|c|c|}
\hline ACD & Thai Cosmetics Regulation \\
\hline $\begin{array}{l}\text { Member Countries shall ensure that } \\
\text { product claims of cosmetic products } \\
\text { comply with the ASEAN Cosmetic } \\
\text { Claims Guideline. In general, } \\
\text { product claims shall be subjected to } \\
\text { national control. As a general rule, } \\
\text { claimed benefits of a cosmetic } \\
\text { product shall be justified by } \\
\text { substantial evidence and/or by the } \\
\text { cosmetic formulation or preparation } \\
\text { itself. The responsible company or } \\
\text { person for placing a product in the } \\
\text { market will be allowed to use their } \\
\text { own scientifically proven data or } \\
\text { clinical data provided for claims } \\
\text { justification. }\end{array}$ & $\begin{array}{l}\text { Thailand does not have specific laws or regulation on cosmetics claims. Claims related to } \\
\text { composition and functions were scoped by definition in the cosmetics act. Other cosmetics } \\
\text { claims and advertisements have been controlled by the consumer protection act B.E. } 2522 \\
\text { which is a general law for all consumer goods and services. The Thai FDA was authorized by } \\
\text { the consumer protection board to fully control cosmetics products on claims and } \\
\text { advertisements. Generally, cosmetics advertisements must not contain a statement which was } \\
\text { unfair to consumers including; (1) statement which must not be false or exaggerated, (2) } \\
\text { statement must not cause misunderstanding, (3) statement must not be unlawful or immoral act, } \\
\text { or have negative impact to national culture, (4) statement must not cause disunity or adversely } \\
\text { affects the unity among the public, and (5) other statements as prescribed in the ministerial } \\
\text { regulation. A statement used in the advertisement which an ordinary person knows that it is not } \\
\text { possible to be true is not prohibited for use in the advertisement. The claimed benefits of a } \\
\text { cosmetic product must be justified by substantial evidence and/or by the cosmetic formulation } \\
\text { or preparation itself. The importer or local manufacturers were allowed to use their own } \\
\text { scientifically proven data or clinical data provided for claims justification. }\end{array}$ \\
\hline
\end{tabular}

It was also specified in the AHCRS that product claims shall be subjected to national control. For Thailand, there might be some different interpretation on claims allowance related to cosmetics function and purpose. This might be caused by the definition and scope of cosmetics purposes of ACD which were wider than Thai regulation as specified earlier in the section of "scope and definition". For example, the claim of "whitening efficacy" may be allowed to be used in other ASEAN member states based on definition of cosmetics in ACD, but it has not been allowed in Thailand because it is considered out of cosmetic scope according to cosmetic definition in Thai cosmetics act. The translation of "whitening" into Thai is allowed to be only "brightening" and "lightening" or other Thai words with similar concept.

It was truly difficult to harmonize claims because of the differences of language, religion and culture have always existed. That was why AHCRS has allowed the cosmetic claims to be subjected to national control. With this technical constraint on claims Harmonisation, there was an impact to companies who made claims concept for a whole region. The claims concept possibly might need to be changed after translation to local language, because the claims might need to be modified or adjusted to comply with local regulation. The international claims which were allowed to use worldwide were not able to be directly translated to exact Thai words such as "whitening", and "anti-hair fall", etcetera. For consumer impact, they might have limitation to access to the product innovations or information which were blocked and filtered by regulators. Consumers might sometimes lost chances to get real information about their selected products or to access new innovations. Consumers might also misunderstand about the product facts. The claims relied on interpretation. The wording in claims might be interpreted differently among experts, industry and consumers. These were also based on attitude, experiences and educational background.

In conclusion, it was considered by key informants that Thailand has complied with this technical area of ACD. Both laws do not require pre-approval for cosmetic claims and advertisements. The justification criteria on cosmetic claims are similar. The minor differences on the scope of claims which related to different cosmetic definitions of both laws, have been discussed and are planned to be adjusted in the future. It was also agreed in AHCRS that cosmetic claims are subjected to national control because of different language, situation, culture and religion. Therefore, the specific wordings for prohibited claims or allowed claims could not be harmonised.

\subsection{GMP}

Thailand had a national GMP guideline which was equivalent to ACD. This GMP guideline has complied in both content and objectives since the baseline in 2008. Both guidelines used the same references which were WHO (GMP for pharmaceutical products), TGA (Australian Code of GMP for therapeutic goods sunscreen products), COLIPA (Cosmetics GMP). The ACD GMP guideline also used the additional references of Good Storage Practice of Malaysia and Guidelines on GMP for traditional medicines of Malaysia. In Thailand, a cosmetics GMP is voluntary. Although, it is not mandated, the Thai FDA has promoted and empowered domestic manufacturers through trainings and/or workshops. Both Thai cosmetics regulation and ACD have provided the same direction on GMP guidelines since the baseline. Thailand has not updated its laws and regulation on cosmetics GMP since then. Please see a comparison between ACD and Thai cosmetics regulation on GMP in Table 5 below. 
Table 5 Comparison between ACD and Thai cosmetics regulation on GMP

\begin{tabular}{|c|c|}
\hline ACD & Thai Cosmetics Regulation \\
\hline
\end{tabular}

As noted, ASEAN cosmetics GMP was developed to offer assistance to the cosmetic industry in compliance with the provision of the ACD. The ASEAN GMP guideline is only a general guideline for the manufacturer to develop its own internal quality management system and procedures. The important objective is the final products must meet the quality standards appropriate to their use to assure consumer's health and benefit. However, to comply with a full ASEAN GMP guideline, the manufacturers may have to invest in either budgets and/or resources. Thailand has various types and sizes of manufacturers with different facilities and capacities. It was discussed among key informants from regulator and industry sector that if the country implemented the full ASEAN GMP immediately, only big companies could survive while small and/or medium companies would no longer exist in such a regulatory environment. This was a big challenge for the government sector to implement ASEAN cosmetics GMP at the local level. The government has decided to develop the primary GMP guideline on the basis of manufacturing standard to help improve the cosmetics industry in Thailand and encourage, step by step, the small and medium enterprises to meet the ASEAN GMP in the future. The primary GMP enforcement was drafted and circulated for public hearing in 2013. The authority has provided training to all sizes of industry sector on this subject. In order to improve the capacity and facility of small and medium enterprises, the budget and resource were the most needs during the development and improvement process.

In conclusion, the Thai cosmetic GMP guideline is similar to the ASEAN cosmetics GMP. This national guideline had been used in Thailand before ACD implementation in 2008. There is no plan to update this full guideline. However, to support the small and medium size business to better prepare themselves for AEC in 2015, the Thai government has established the primary GMP guideline which is planned to be implemented within 2014.

\section{Conclusion}

Overall, the Thai cosmetic regulation is highly compliant with ACD. Some technical areas were similar at baseline or before ACD adoption. The areas of "definition and scope", "product claims" and "GMP" were similar at baseline. The "ingredients" listing" of Thailand was a bit different from ACD at baseline, but it was finally updated to comply with ACD ingredients' listing including finished product control after full implementation in 2012. The content or details of ingredients in each particular category are still different because the ingredients' listing in ACD has been updated from time to time based on the EU updated list. Moreover, the Thai legal process to transpose the adopted updated list may take 6-12 months. For "labelling requirements", Thailand had an intention to update the country law and regulation to comply with ACD. The necessary requirements in ACD have already been covered by Thai labelling regulation. However, there are still some country specific requirements which still exist, because of country context and previous experiences.

The ASEAN Harmonisation in technical areas of cosmetics could not be completely done with the exact ACD format for the member countries with existing laws i.e. Thailand Indonesia, and Malaysia. The adopted content in ACD must be aligned with the existing laws and other relevant laws which is a truly technically difficult process. Each country still had its own needs and limitations which must be respected by the others. The gap between Thai regulation and ACD and its impacts will be raised to decision makers of both regulator and industry sectors to consider for future improvement. The main objectives of AHCRS on consumer protection and trade barriers elimination could be achieved in some areas, but not all at this initial stage. As previously stated about ASEAN regulatory environment (McDougall, 2011), it could be said, from this study, that Harmonisation has happened, even though it is not complete as expected. It has happened in the ASEAN way.

This study was mainly focused on the Thailand situation. The further study should be expanded to other ASEAN member countries to evaluate the level of ACD compliance. The compliance status of each particular country could be used to measure the success of ASEAN Harmonised Cosmetics Regulatory Scheme implementation in the region. It could also help to encourage regulator and industry sectors of each member state to focus on existing problems. More effort should be spent on how to achieve successful Harmonisation or revising ACD. This is to better prepare the member states to be ready for a single ASEAN Economic Community in 2015. 


\section{Acknowledgement}

The authors acknowledge the help of Stephen Pinder, International Program Manager for Postgraduate Studies in Epidemiology at Mahidol University, Thailand, a native English speaker for help in proofreading this manuscript.

This is the part of the training of Neeranard Jinachai for a Ph.D. in the graduate program in Social and Administrative Pharmacy (International Program), Faculty of Pharmaceutical Sciences, Chulalongkorn University.

[1] Information $\quad$ References:
http://www.hsa.gov.sg/publish/hsaportal/en/health_products_regulation/cosmetic_products/asean_regulatory.html

